Published in final edited form as:

Curr Opin Hematol. 2015 May ; 22(3): 227-233. doi:10.1097/MOH.0000000000000136.

\title{
Update of hematopoietic cell transplantation for sickle cell disease
}

\author{
Mark C. Walters \\ Jordan Family Director, Blood and Marrow Transplant Program, Division of Hematology/Oncology/ \\ BMT, UCSF Benioff Children's Hospital, Oakland, California, USA
}

\begin{abstract}
Purpose of review-Hematopoietic cell transplantation (HCT) is a curative therapy for sickle cell disease (SCD) that is utilized very rarely because of limited allogeneic donor availability, limited healthcare resources needed to expand the treatment to regions in the world where most affected individuals reside, and by a view among SCD experts that HCT lacks the evidential rigor with short and long-term toxicity profiles that together might support its broader application.
\end{abstract}

Recent findings-In this update, recent advances focused on donor selection, reduced toxicity preparation for HCT, and treatment of young adults will be presented. The current status of conventional bone marrow transplantation with a human leukocyte antigen-identical sibling donor is summarized.

Summary-HCT for SCD is curative in almost all children who have a human leukocyte antigen-matched sibling donor. The future of this therapy will hinge on expanding the number of individuals who might be treated.

\section{Keywords}

alternate donor; hematopoietic cell transplantation; sickle cell disease

\section{INTRODUCTION}

Approximately 10-15 years ago, several studies from North America and Europe, which analyzed prospective patient series, observed that sickle cell disease (SCD) might be cured in children with severe manifestations of SCD who were treated by human leukocyte antigen-identical (HLA-ID) sibling bone marrow transplantation [1-3]. These and subsequent studies also established that engraftment of healthy donor cells was associated with cessation of sickle-related clinical complications, and protection from progressive endorgan vaso-occlusive-related injury in nearly all cases $\left[4,5^{\square}, 6-8\right]$. While these successful outcomes were encouraging, there were several important impediments to broader utilization of hematopoietic cell transplantation (HCT) that were illustrated by these and more recent

Correspondence to Mark C. Walters, Jordan Family Director, BMT Program, UCSF Benioff Children's Hospital, Oakland, 747 52nd Street, Oakland, CA 94609, USA. Tel: +1 510428 3374; mwalters@ mail.cho.org.

Conflicts of interest

The author is a Medical Director of the ViaCord Processing Laboratory - a family umbilical cord blood banking facility - and has received honoraria from Biogen IDEC and Bluebird Bio, Inc., for advisory work in the past 12 months. 
studies. First, very few individuals had suitable donors, and it was estimated that $14 \%$ of sickle cell anemia individuals will have an HLA-ID sibling donor and $19 \%$ will have a very well matched unrelated marrow donor in the volunteer registry $\left[{ }^{\mathbb{m}}, 10\right]$. Secondly, the treatment itself carried a risk of dying and of treatment-related morbidity caused by graftversus-host disease (GVHD), with a high risk of infertility [8]. These considerations have caused reluctance among affected persons and their families, and more importantly, by SCD experts, about recommending and pursuing this curative therapy $[11,12]$. Finally, the initial experiences were limited almost exclusively to pediatric-aged recipients in lieu of adults with SCD. As a consequence, the registries of the European Blood and Marrow Transplant (EBMT) and the Center for International Blood and Marrow Transplant Research (CIBMTR) reported only 611 and 627 patients, respectively, receiving transplantations for SCD, as of 2013 [13]. This view about the limited utility of HCT in treating sickle cell anemia was not dissuaded in the recent Evidence-Based Management of Sickle Cell Disease treatise published in 2014 by the National Heart, Lung, and Blood Institute, in which the expert panel concluded that 'additional research is still needed that addresses the potential risks of this therapy (e.g. failure of engraftment and chronic GVHD) before HCT can become a widely used therapy' $\left[14^{-}\right]$.

\section{KEY POINTS}

-

HLA-ID sibling bone marrow transplantation in children with severe SCD results in a curative outcome in more than $90 \%$ of the recipients.

Bone marrow transplantation for SCD is constrained by a paucity of suitable donors for most individuals who have a clinically severe phenotype.

- $\quad$ New developments in alternate donor transplantation are very likely to expand the availability of this treatment option for SCD.

The present brief review will highlight several recent advances in alternate donor transplantation, reduced toxicity transplant preparation that focuses on the immunosuppressive effect in lieu of myeloablation to establish donor hematopoiesis, and on transplantation in young adult recipients. Together, these early studies project an expansion of this treatment option by improvement in alternate donor transplantation and by reduced toxicity preparation that might make it possible to treat adult patients with an acceptable level of toxicity.

\section{HUMAN LEUKOCYTE ANTIGEN-IDENTICAL SIBLING HEMATOPOIETIC CELL TRANSPLANTATION}

Outcomes after HLA-ID sibling bone marrow transplantation from a series involving individuals who were treated 10 years ago and longer established a benchmark event-free survival (EFS) probability of approximately $85 \%$, with most of the failures occurring as a consequence of graft rejection/disease recurrence [1-3,15]. In patients treated after year 2000, a 5-year EFS of $95 \%$ was observed after modifying the conditioning regimen to 
include thymoglobulin [rabbit antithymocyte globulin (rATG)] [2,16 ${ }^{\mathbf{m}}$. The current outcomes, as compiled from the registry data and the individual-center studies, together show that an expectation of a higher cure rate in the current era has been realized, and confirm that HCT is an important therapeutic option to consider in patients who experience serious complications of SCD.

In a series of 40 patients from Black-African and non-Black-African origins treated in Rome, Italy, the overall survival and EFS both were 91\% after an HLA-ID sibling bone marrow transplantation with conventional myeloablative preparation [17]. Of interest, among the 27 recipients of Black-African descent, all patients from Nigeria received the busulfan/cyclophosphamide/rATG backbone supplemented with fludarabine (Flu) in the conditioning regimen. This approach was associated with three of the 27 recipients dying, and the remainder surviving free of SCD. Of interest, none of the other13 non-Black-African patients conditioned with busulfan/cyclophosphamide/rATG without Flu died, and all survived free of SCD. A single center in Atlanta observed 24 of the 25 patients surviving free of SCD, who were treated between 1993 and 2007, after preparation with busulfan/ cyclophosphamide/horse ATG before an HLA-ID sibling HCT [18]. In another contemporary series of 50 children treated in Belgium between 1988 and 2013, the EFS after HLA-ID sibling HCT was $85.6 \%$, and $94.1 \%$ of the recipients survived [16 ${ }^{\mathbf{m}}$. Of interest, all children treated since 1995 had hydroxyurea administered well before HCT, which comprised a group of 38 recipients, as first reported in 2004 [19]. Thirty-seven of these individuals survive free of SCD, with an 8-year estimate of EFS that is $97.1 \%$, and which is significantly higher compared to the EFS in those who did not receive hydroxyurea before HCT $(P<0.001)$. Finally, in another recent series of children treated in New York, who received a combination of busulfan, Flu, and alemtuzumab before HLA-ID sibling HCT, all 18 children survived free of SCD after HCT [20] (Table 1). Of the 135 patients compiled from the four recent published reports listed in Table 1, 129 patients survived (96\%) and 125 survived free of SCD (93\%). Taken together, these updated results indicate that HLA-ID sibling HCT can be expected to cure $90-95 \%$ of pediatric recipients with severe SCD following a conventional conditioning regimen in this current era[21].

The use of umbilical cord blood (UCB) is of interest, due primarily to a lowered risk of GVHD after UCB transplantation compared to marrow transplantation. However, a GVHD benefit is balanced by a higher rate of graft rejection and a prolonged period of hematologic recovery that typically accompanies UCB transplantation [22]. The most recent update of HLA-ID sibling UCB transplantation compared marrow and UCB transplant outcomes with CIBMTR and EBMT registry data from US and European transplant centers, and compiled 485 recipient cases with thalassemia major and SCD [23]. The overall 6-year disease-free survival in 160 patients with SCD, who were treated between 1994 and 2005 by either source of hematopoietic cells, was $92 \pm 2 \%$. The disease-free survival after UCB transplantation was $90 \pm 5 \%$ in 30 patients and it was $92 \pm 2 \%$ after bone marrow transplantation in 130 patients. In this investigation, the outcome after UCB transplantation was influenced by the use of methotrexate for GVHD prophylaxis, which was a significant variable in a multivariate analysis of factors influencing the probability of disease-free survival (hazard ratio 3.81, $P=0.004$ ). None of the patients developed chronic extensive GVHD and none of the patients died of GVHD after UCB transplantation. This benefit, in 
terms of a lower GVHD risk, was also realized when marrow and UCB from the same donor were used when the UCB cell dose was judged too small to support engraftment [24]. Thus, while it appears that UCB and marrow from HLA-ID donors might be used interchangeably to support $\mathrm{HCT}$ for SCD, the use of UCB from a sibling donor appears to extend a benefit in terms of a lower risk of acute and chronic GVHD.

Together, these reports generate strong evidence that HLA-ID sibling HCT for SCD has a very high potential of a clinical benefit. It is not feasible to design and conduct a randomized clinical trial, comparing HLA-ID sibling HCT to supportive care because too few individuals have an HLA-ID sibling donor and because informative outcomes that take into account the long-term benefits of surviving free of SCD, as might be required in a conventional prospective clinical trial, take longer than 2-5 years to demonstrate. Nonetheless, the preponderance of evidence from these trials strongly suggests that HLA-ID sibling HCT for SCD carries a significant clinical benefit, and that this treatment, as applied in the current era, is not an experimental therapeutic intervention.

\section{HEMATOPOIETIC CELL TRANSPLANTATION IN ADULT RECIPIENTS}

The possibility that conventional HCT might be pursued in young adults in SCD was suggested by a study of 15 patients from a French group and by parallel efforts in thalassemia major in which myeloablative but reduced toxicity regimens had been developed to reduce the risk of transplant-related mortality $[25,26]$. However, there is an over-riding concern that cumulative organ damage caused by vaso-occlusion will cause an unacceptable risk of transplantation, which has limited studies in this population. In contrast, nonmyeloablative (NMA) and reduced-intensity conditioning regimens are used routinely to establish engraftment of donor hematopoietic cells in adults with hematologic malignancies. The success of immunoablative but reduced-intensity regimens suggests that an immunologic barrier rather than a strict requirement of empty 'hematopoietic space' is most important to ensuring engraftment of donor hematopoietic stem cells. Although NMAconditioning regimens have been successful in adults with hematological malignancies, these have been less successful in hemoglobinopathies [27-29]. But there are more recent trials to suggest that an optimal regimen might soon be defined (see Table $2[26,30,31 \mathbf{\square}$, $32])$.

Hsieh et al. [31 32$]$ demonstrated stable donor engraftment in adult SCD patients following NMA HSCT from HLA-matched sibling donors. Between 2004 and 2013, 30 patients with severe disease who were 16-65 years of age were treated by a NMA combination of alemtuzumab ( $1 \mathrm{mg} / \mathrm{kg}$ in divided doses), total body irradiation (300 cGy), and sirolimus followed by HLA-ID sibling filgrastim mobilized peripheral blood stem cell transplantation. Sirolimus alone was used for GVHD prophylaxis, and $87 \%$ of the recipients had long-term engraftment without acute or chronic GVHD. While sirolimus was discontinued in 15 of the 30 recipients, in the remaining recipients, it was extended due to lymphohematopoietic chimerism that was judged too low to prevent a late graft rejection. The selection of sirolimus appeared pivotal to the very good outcome because of its inhibitory effect on effector T-cell proliferation and viability while preserving T-regulatory cells that are required for tolerance, and because sirolimus does not appear to cause posterior 
reversible encephalopathy syndrome unlike other calcineurin inhibitors. Posterior reversible encephalopathy syndrome has been observed in approximately 10-20\% of the sickle cell recipients who receive cyclosporine post-HCT for GVHD prevention, and is thus a leading contributor to adverse events after HCT for SCD $[8,33]$.

The cohort had a clinical benefit even when there was a minority of donor T cells after HCT. Specifically, the mean hemoglobin level in women and men improved from 8.1 and $8.9 \mathrm{~g} / \mathrm{dl}$, respectively, before HCT to 12.7 and $13.7 \mathrm{~g} / \mathrm{dl}$ after HCT $(P<0.001)$. There were similarly significant improvements in the reticulocyte count, serum bilirubin, and the lactate dehydrogenase levels. There were nine patients with a history of stroke before transplantation, who had stable brain appearance by MRI after HCT. The mean tricuspid regurgitant jet velocity before HCT declined from 2.84 to $2.33 \mathrm{~m} / \mathrm{s} 3$ years after HCT.

Eleven patients who received chronic opioid treatment for pain control had significant dose reductions by 6 months after HCT and six stopped the opioids completely. In summary, there were significant benefits of mixed chimerism in this cohort that translated into clinical and subclinical improvements in disease expression after HCT.

\section{ALTERNATIVE SOURCES OF DONOR HEMATOPOIETIC CELLS}

The current experience of unrelated donor UCB transplantation for SCD is quite limited, but it illustrates the challenges yet to be overcome. In an analysis by the CIBMTR that included patients with thalassemia and SCD, 16 children had SCD [34]. Nine of the 16 SCD patients received myeloablative conditioning. Seven of the 16 patients achieved neutrophil recovery a median of 22 days after transplantation with full donor chimerism. Eight of the 16 patients were alive and disease-free, with an overall survival probability of $62 \pm 9 \%$. In multivariate analysis, disease-free survival was higher if the UCB unit contained more than $5 \times 10^{7}$ total nucleated cells $/ \mathrm{kg}$ recipient weight (hazard ratio $0.4, P=0.01$ ). The cumulative incidence of chronic GVHD in all patients was $16 \pm 4 \%$. Contemporary to this registry experience, enrollment to the UCB arm of an unrelated donor HCT trial in the United States for SCD was stopped early due to a high rate of graft rejection following a reduced intensity regimen of Campath, Flu, and melphalan [35]. Eight children received UCB from unrelated donors matched at five or six of the six HLA-antigens. Five patients experienced autologous marrow recovery after UCB transplantation and one died of chronic GVHD. Three of the eight patients survived disease-free after receiving this reduced-intensity regimen.

Together, these studies suggest that whereas a successful outcome is possible after unrelated donor UCB transplantation for SCD if one adheres to strict criteria for HLA-matching, conditioning regimen intensity, and a minimum cell dose, these features alone are not sufficient to ensure a successful outcome. Thus, it is very likely that improved outcomes will rely upon novel conditioning regimens, alternate donor/recipient HLA-matching algorithms, screening for anti-HLA antibodies, and perhaps an even higher cell-dose target to overcome the problems of graft rejection and GVHD that currently impede progress. The possibility of unrelated donor bone marrow transplantation is an option, but donor availability may constrain this option, as expanded upon below. 


\title{
HUMAN LEUKOCYTE ANTIGEN HAPLO-IDENTICAL HEMATOPOIETIC CELL TRANSPLANTATION FOR SICKLE CELL DISEASE
}

As noted above, lacking a suitable donor is the major barrier to HCT for SCD. A muchexpanded availability of HLA-compatible unrelated donors would be necessary to make HCT a feasible therapeutic option. Donors who are matched at six (HLA-A, B, and DRB1 loci) to 10 HLA antigens (including HLA-C and DQB1 loci) can be identified via the National Marrow Donor Program in approximately $75 \%$ of white recipients of European descent; however, the likelihood of identifying a similarly HLA-matched unrelated donor is less likely in other ethnic groups due to under-representation of these groups in the volunteer donor pool and to greater HLA diversity [ $9^{-0}$. The lowest probability at $16 \%$ occurs in blacks of South or Central American descent. Thus, at present, it is very unlikely that a suitable unrelated donor will be identified for most individuals with SCD. For these individuals, utilizing hematopoietic cells from an HLA-mismatched related donor for HCT would be particularly useful. This possibility was suggested in a study of HLA haploidentical bone marrow transplantation in severe SCD that was pioneered by the transplant team at Johns Hopkins University [36]. This approach employed a NMA combination of cyclophosphamide, ATG, and Flu with $200 \mathrm{cGy}$ total body irradiation before HCT. After the marrow infusion, postgrafting high-dose cyclophosphamide was administered to accomplish in-vivo T-cell depletion and to facilitate durable engraftment of the donor cells without severe GVHD. In a pilot investigation, 14 recipients of haploidentical HCT were treated and all had prompt recovery after HCT, although six developed graft rejection at a median of 151 days after HCT and one patient had low-level donor chimerism with severe anemia after HCT. Nonetheless, $50 \%$ of the patients had stable donor engraftment and cessation of sickle-related complications, and none had chronic GVHD. If the barrier of graft rejection can be reduced, this would broaden the availability of transplantation to a much larger fraction of patients who otherwise satisfy eligibility requirements but lack a suitable unrelated donor.

\section{CONCLUSION}

Hematopoietic cell transplantation for SCD has evolved from an initial case report in 1984 [37] to become an important therapeutic option, which has curative potential. Today, almost all children treated by HLA-ID sibling bone marrow transplantation will survive free of SCD. The future of this treatment, however, hinges on the ability to broaden the availability of donors and to achieve success rates after alternate donor HCT that approach those observed after HLA-ID sibling HCT. The future of HCT also will rely upon better communication of the natural history of SCD between families and their providers, and by early and frank discussions about HCT as an important if not preferred treatment option for those who have severe SCD [11,38].

\section{Acknowledgments}

\author{
None. \\ Financial support and sponsorship
}


None.

\section{REFERENCES AND RECOMMENDED READING}

Papers of particular interest, published within the annual period of review, have been highlighted as:

of special interest

$\square$ of outstanding interest

1. Walters MC, Storb R, Patience M, et al. Impact of bone marrow transplantation for symptomatic sickle cell disease: an interim report. Blood. 2000; 95:1918-1924. [PubMed: 10706855]

2. Bernaudin F, Socie G, Kuentz M, et al. Long-term results of related myeloablative stem-cell transplantation to cure sickle cell disease. Blood. 2007; 110:2749-2756. [PubMed: 17606762]

3. Vermylen C, Cornu G, Ferster A, et al. Haematopoietic stem cell transplantation for sickle cell anaemia: the first 50 patients transplanted in Belgium. Bone Marrow Transplant. 1998; 22:1-6. [PubMed: 9678788]

4. Bockenmeyer J, Chamboredon E, Missud F, et al. Development of psychological and intellectual performance in transplanted sickle cell disease patients: a prospective study from pretransplant period to 5 years after HSCT. Arch Pediatr. 2013; 20:723-730. [PubMed: 23769628]

5ロ. Bodas P, Rotz S. Cerebral vascular abnormalities in pediatric patients with sickle cell disease after hematopoietic cell transplant. J Pediatr Hematol Oncol. 2014; 36:190-193. Forty-five SCD recipients were evaluated by cerebral MRI/magnetic resonance angiography after HCT, and $84 \%$ had stable or improved appearance. [PubMed: 24327127]

6. Dallas MH, Triplett B, Shook DR, et al. Long-term outcome and evaluation of organ function in pediatric patients undergoing haploidentical and matched related hematopoietic cell transplantation for sickle cell disease. Biol Blood Marrow Transplant. 2013; 19:820-830. [PubMed: 23416852]

7. Mynarek M, Bettoni da Cunha Riehm C, Brinkmann F, et al. Normalized transcranial Doppler velocities, stroke prevention and improved pulmonary function after stem cell transplantation in children with sickle cell anemia. Klin Padiatr. 2013; 225:127-132. [PubMed: 23625683]

8. Walters MC, Hardy K, Edwards S, et al. Pulmonary, gonadal, and central nervous system status after bone marrow transplantation for sickle cell disease. Biol Blood Marrow Transplant. 2010; 16:263272. [PubMed: 19822218]

9 G. Gragert L, Eapen M, Williams E, et al. HLA match likelihoods for hematopoietic stem-cell grafts in the U.S. registry. N Engl J Med. 2014; 371:339-348. A comprehensive analysis of the current probability of finding a very well matched unrelated donor for HCT. [PubMed: 25054717]

10. Walters MC, Patience M, Leisenring W, et al. Barriers to bone marrow transplantation for sickle cell anemia. Biol Blood Marrow Transplant. 1996; 2:100-104. [PubMed: 9118298]

11. Roth M, Krystal J, Manwani D, Driscoll C, Ricafort R. Stem cell transplant for children with sickle cell anemia: parent and patient interest. Biol Blood Marrow Transplant. 2012; 18:1709-1715. [PubMed: 22659467]

12. van Besien K, Koshy M, Anderson-Shaw L, et al. Allogeneic stem cell transplantation for sickle cell disease. A study of patients' decisions. Bone Marrow Transplant. 2001; 28:545-549. [PubMed: 11607766]

13. Gluckman E. Allogeneic transplantation strategies including haploidentical transplantation in sickle cell disease. Hematology Am Soc Hematol Educ Program. 2013; 2013:370-376. [PubMed: 24319206]

14. Yawn BP, Buchanan GR, Afenyi-Annan AN, et al. Management of sickle cell disease: summary of the 2014 evidence-based report by expert panel members. J Am Med Assoc. 2014; 312:10331048. Evidence-based analysis of current management of SCD that is notable for lacking recommendations about HCT. 
15. Panepinto JA, Walters MC, Carreras J, et al. Matched-related donor transplantation for sickle cell disease: report from the Center for International Blood and Transplant Research. Br J Haematol. 2007; 137:479-485. [PubMed: 17459050]

16 . Dedeken L, Le PQ, Azzi N, et al. Haematopoietic stem cell transplantation for severe sickle cell disease in childhood: a single centre experience of 50 patients. Br J Haematol. 2014; 165:402408. A benefit of hydroxyurea administration before HLA-ID sibling HCT for SCD was strongly suggested in this study. [PubMed: 24433465]

17. Lucarelli G, Isgro A, Sodani P, et al. Hematopoietic SCT for the Black African and non-Black African variants of sickle cell anemia. Bone Marrow Transplant. 2014; 49:1376-1381. [PubMed: 25068420]

18. McPherson ME, Hutcherson D, Olson E, et al. Safety and efficacy of targeted busulfan therapy in children undergoing myeloablative matched sibling donor BMT for sickle cell disease. Bone Marrow Transplant. 2011; 46:27-33. [PubMed: 20305698]

19. Brachet C, Azzi N, Demulder A, et al. Hydroxyurea treatment for sickle cell disease: impact on haematopoietic stem cell transplantation's outcome. Bone Marrow Transplant. 2004; 33:799-803. [PubMed: 14767501]

20. Bhatia M, Jin Z, Baker C, et al. Reduced toxicity, myeloablative conditioning with BU, fludarabine, alemtuzumab and SCT from sibling donors in children with sickle cell disease. Bone Marrow Transplant. 2014; 49:913-920. [PubMed: 24797180]

21. Soni S, Gross TG, Rangarajan H, et al. Outcomes of matched sibling donor hematopoietic stem cell transplantation for severe sickle cell disease with myeloablative conditioning and intermediate-dose of rabbit antithymocyte globulin. Pediatr Blood Cancer. 2014; 61:1685-1689. [PubMed: 24740582]

22. Kekre N, Antin JH. Hematopoietic stem cell transplantation donor sources in the 21 st century: choosing the ideal donor when a perfect match does not exist. Blood. 2014; 124:334-343. [PubMed: 24914138]

23. Locatelli F, Kabbara N, Ruggeri A, et al. Outcome of patients with hemoglobinopathies given either cord blood or bone marrow transplantation from an HLA-identical sibling. Blood. 2013; 122:1072-1078. [PubMed: 23692854]

24․ Soni S, Boulad F, Cowan MJ, et al. Combined umbilical cord blood and bone marrow from HLA-identical sibling donors for hematopoietic stem cell transplantation in children with hemoglobinopathies. Pediatr Blood Cancer. 2014; 61:1690-1694. First study of a benefit in terms of reduced risk of GVHD in SCD after combining UCB and marrow from the same sibling donor. [PubMed: 24803091]

25. Bernardo ME, Piras E, Vacca A, et al. Allogeneic hematopoietic stem cell transplantation in thalassemia major: results of a reduced-toxicity conditioning regimen based on the use of treosulfan. Blood. 2012; 120:473-476. [PubMed: 22645178]

26. Kuentz M, Robin M, Dhedin N, et al. Is there still a place for myeloablative regimen to transplant young adults with sickle cell disease? Blood. 2011; 118:4491-4492. Author reply 4492-4493. [PubMed: 22021455]

27. Horan JT, Liesveld JL, Fenton P, et al. Hematopoietic stem cell transplantation for multiply transfused patients with sickle cell disease and thalassemia after low-dose total body irradiation, fludarabine, and rabbit antithymocyte globulin. Bone Marrow Transplant. 2005; 35:171-177. [PubMed: 15531901]

28. Iannone R, Casella JF, Fuchs EJ, et al. Results of minimally toxic nonmyeloablative transplantation in patients with sickle cell anemia and beta-thalassemia. Biol Blood Marrow Transplant. 2003; 9:519-528. [PubMed: 12931121]

29. Wu CJ, Gladwin M, Tisdale J, et al. Mixed haematopoietic chimerism for sickle cell disease prevents intravascular haemolysis. Br J Haematol. 2007; 139:504-507. [PubMed: 17910640]

30. Krishnamurti L, Kharbanda S, Biernacki MA, et al. Stable long-term donor engraftment following reduced-intensity hematopoietic cell transplantation for sickle cell disease. Biol Blood Marrow Transplant. 2008; 14:1270-1278. [PubMed: 18940682]

31‥ Hsieh MM, Fitzhugh CD, Weitzel RP, et al. Nonmyeloablative HLA-matched sibling allogeneic hematopoietic stem cell transplantation for severe sickle cell phenotype. J Am Med 
Assoc. 2014; 312:48-56. Extended follow-up with analysis of end-organ function in a large cohort of adults with SCD treated by NMA HCT.

32. Hsieh MM, Kang EM, Fitzhugh CD, et al. Allogeneic hematopoietic stem-cell transplantation for sickle cell disease. N Engl J Med. 2009; 361:2309-2317. [PubMed: 20007560]

33. Walters MC, Sullivan KM, Bernaudin F, et al. Neurologic complications after allogeneic marrow transplantation for sickle cell anemia. Blood. 1995; 85:879-884. [PubMed: 7849310]

34. Ruggeri A, Eapen M, Scaravadou A, et al. Umbilical cord blood transplantation for children with thalassemia and sickle cell disease. Biol Blood Marrow Transplant. 2011; 17:1375-1382.

[PubMed: 21277376]

35. Kamani NR, Walters MC, Carter S, et al. Unrelated donor cord blood transplantation for children with severe sickle cell disease: results of one cohort from the phase II study from the Blood and Marrow Transplant Clinical Trials Network (BMT CTN). Biol Blood Marrow Transplant. 2012; 18:1265-1272. [PubMed: 22343376]

36. Bolanos-Meade J, Fuchs EJ, Luznik L, et al. HLA-haploidentical bone marrow transplantation with posttransplant cyclophosphamide expands the donor pool for patients with sickle cell disease. Blood. 2012; 120:4285-4291. [PubMed: 22955919]

37. Johnson FL, Look AT, Gockerman J, et al. Bone-marrow transplantation in a patient with sicklecell anemia. N Engl J Med. 1984; 311:780-783. [PubMed: 6382010]

38. Hankins J, Hinds P, Day S, et al. Therapy preference and decision-making among patients with severe sickle cell anemia and their families. Pediatr Blood Cancer. 2007; 48:705-710. [PubMed: $16732581]$ 


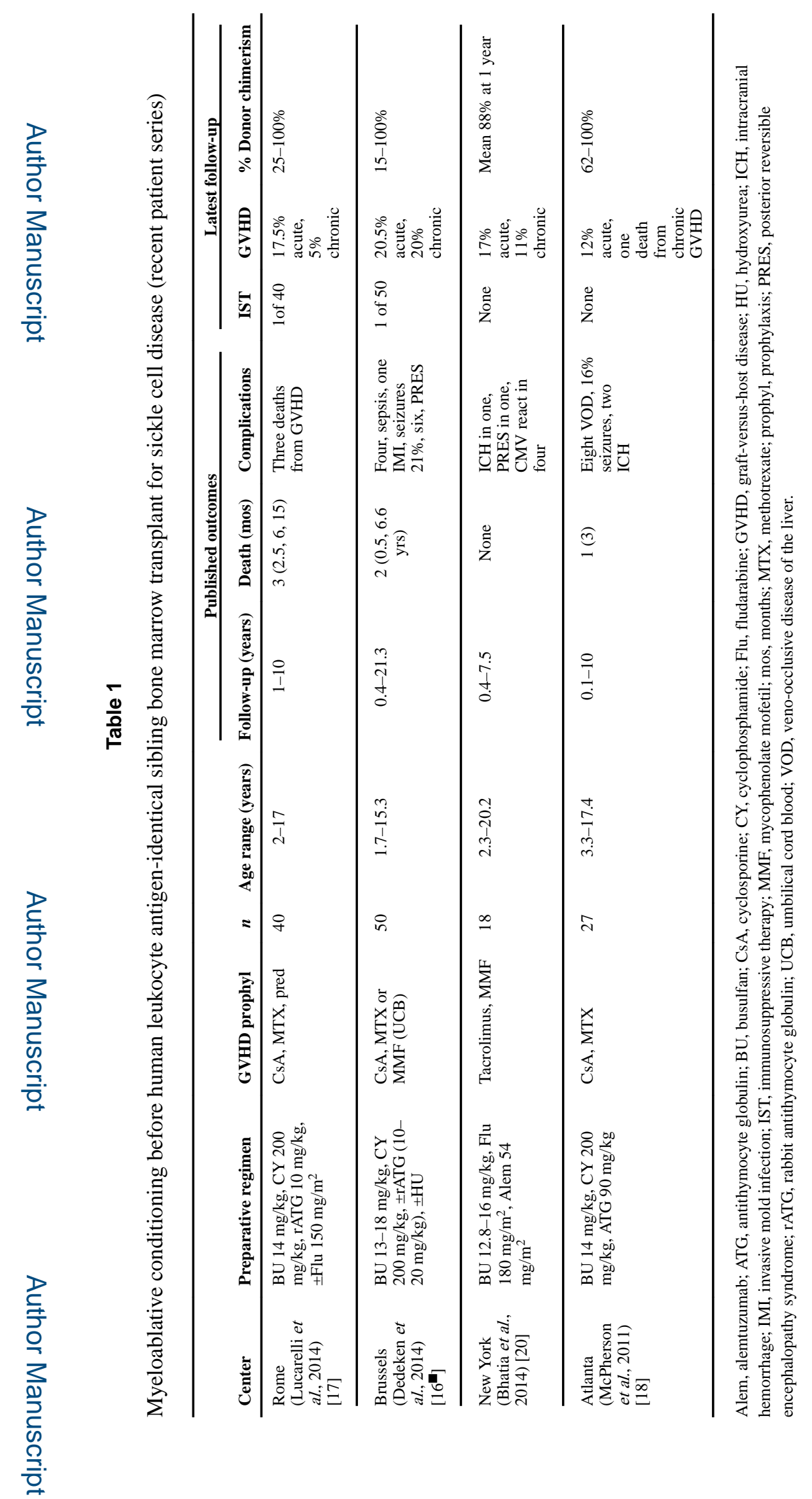

Curr Opin Hematol. Author manuscript; available in PMC 2016 September 27. 


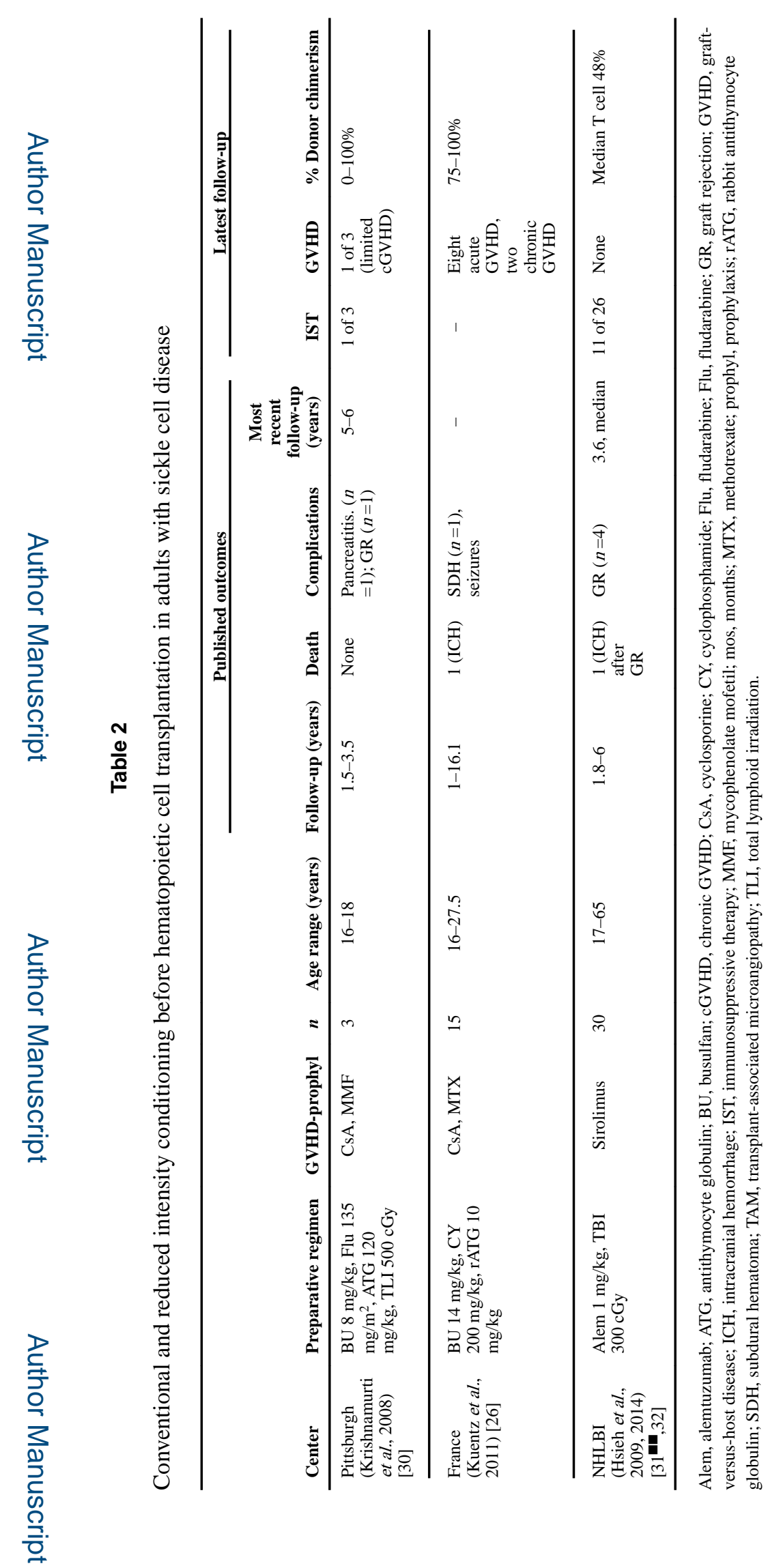

Curr Opin Hematol. Author manuscript; available in PMC 2016 September 27. 